\title{
eCommons@AKU
}

November 2004

\section{Sensory hypoinnervation in club foot}

MAhmed

Aga Khan University

NAhmed

K.M. Khan

masood umer

Aga Khan University, masood.umer@aku.edu

H. Rashid,

See next page for additional authors

Follow this and additional works at: http://ecommons.aku.edu/pakistan_fhs_mc_surg_surg

Part of the Orthopedics Commons

\section{Recommended Citation}

Ahmed, M., Ahmed, N., Khan, K., umer, m., Rashid,, H., Hashmi, P. (2004). Sensory hypoinnervation in club foot. J Bone Joint Surg Br., 86(8), 1163-1169.

Available at: http://ecommons.aku.edu/pakistan_fhs_mc_surg_surg/227 
Authors

M Ahmed; N Ahmed; K. M. Khan; masood umer; H. Rashid,; and Pervaiz Hashmi 


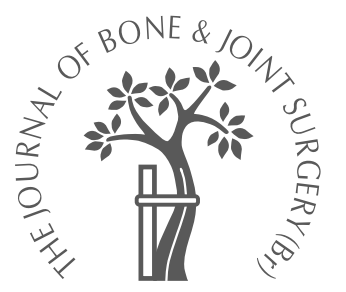

M. Ahmed,

N. Ahmed,

K. M. Khan,

M. Umer,

H. Rashid,

P. Hashmi,

M. Umar

From Aga Khan

University, Karachi, Pakistan.

\section{Sensory hypoinnervation in club foot}

We have compared the density of nerve fibres in the synovium in club foot with that of specimens obtained from the synovium of the hip at operations for developmental dysplasia. The study focused on the sensory neuropeptides substance P; calcitonin generelated peptide; protein gene product 9.5 , a general marker for mature peripheral nerve fibres; and growth associated protein 43, a neuronal marker for new or regenerating nerve fibres. In order to establish whether there might be any inherent difference we analysed the density of calcitonin gene-related peptide-positive nerve fibres in the hip and ankle joints in young rats.

Semi-quantitative analysis showed a significant reduction in the number of sensory and mature nerve fibres in the synovium in club foot compared with the control hips. Calcitonin gene-related peptide (CGRP) positive fibres were reduced by $28 \%$, substance P-positive fibres by $36 \%$ and protein gene product 9.5 -positive fibres by $52 \%$ in club foot. The growth associated protein 43-positive fibres also seemed to be less in six samples of club foot. No difference in the density of CGRP-positive nerve fibres was observed in the synovium between ankle and hip joints in rats.

The lack of sensory input may be responsible for the fibrosis and soft-tissue contractures associated with idiopathic club foot.

The aetiology of idiopathic club foot remains unknown. Chromosomal, embryonic, ontogenic, myogenic, vascular and neurogenic causes have all been advanced. ${ }^{1}$ The neurogenic theory suggests that a primary defect in the nervous system creates a predominance of type 1-muscle fibres leading to contractile imbalance and eventual club foot deformity., $\mathrm{A}$ number of studies have supported the concept of a neuronal influence on musculoskeletal development. Abnormal growth of the foot has been observed in infants with injury to the sciatic nerve. ${ }^{4,5}$ Similarly, children exposed to the drug thalidomide in utero developed limb deformities probably due to peripheral neuropathy in the embryo. ${ }^{6,7}$ Patients with neurogenic defects exhibited asymmetry of leg length, osteoporosis, ectopic bone formation and excessive callus formation during fracture healing. ${ }^{8-11}$ In club foot, the soft tissues on the plantar, medial and posterior aspects of the foot, ankle and distal leg are fibrosed and shortened. $^{12}$ It is uncertain whether these structures have actually contracted or if they have simply become shortened by conforming to the contours of the abnormally shaped tarsal bones. The cause of soft-tissue contrac- ture remains unknown and may be considered a factor in provoking skeletal changes. ${ }^{12}$

A variety of neuronal mediators, so called neuropeptides present in the central and peripheral nervous system, exert trophic effects in several tissues in addition to nociception, vasoaction and pro-inflammation. ${ }^{13,14}$ The sensory neuropeptides substance $\mathrm{P}(\mathrm{SP})$ and calcitonin gene-related peptide (CGRP) not only have nociceptive, vasoregulatory and proinflammatory effects, but have also been shown to stimulate cell proliferation and angiogenesis. ${ }^{15-18}$ The soft-tissue contractures in club foot may be due to abnormal innervation leading to local tissue imbalance in the levels of neuropeptides. We have analysed the density of nerve fibres containing the sensory neuropeptides SP, CGRP, protein gene product 9.5 (PGP 9.5, mature nerve fibres) and growth associated protein (GAP 43, new nerve fibres) in the synovium of the subtalar joint in patients with idiopathic club foot by immunohistochemistry. The density of the nerve fibres was compared with that in the synovium of the capsule of the hip joint in patients with developmental dysplasia. In order to assess the difference in the density of nerve fibres in the 
synovium of the ankle and hip joints, the number of CGRPpositive nerve fibres was also analysed in these joints in young rats.

\section{Patients and Methods}

Specimen collection. A pilot study was undertaken on two children with club foot and two with developmental dysplasia of the hip (DDH) where the size and localisation of the biopsies harvested from the subtalar and hip joints were standardised. Two surgeons (MU, HR) who regularly operate on children with club foot and DDH obtained these samples. In patients with club foot, the specimens were taken from the medial side of subtalar joint and in those with DDH from the anterior part of the capsule of the hip joint. The typical histological features of synovium were identified with superficial and deep layers, villi and blood vessels. A specimen with a mean diameter of $6 \mathrm{~mm}$ for the club feet and $10 \mathrm{~mm}$ for the hips was sufficient for the identification and semi-quantitative analysis of the synovial nerve fibres.

For the main study specimens were taken from the medial side of subtalar joint during surgery on 24 patients with idiopathic club foot. None had any associated neurological abnormality. All the children had undergone serial casting before operation, but no previous foot surgery. There were 15 boys and nine girls; their mean age was 14 months (6 to 30). Eight patients had bilateral operations (16 feet) and 16 unilateral (16 feet). For the bilateral operations only the right side was assessed, irrespective of the degree of deformity.

The control material consisted of biopsies obtained from the anterior part of the capsule of 22 hip joints of patients undergoing surgery for idiopathic DDH. None of these patients had any associated neurological abnormality. There were 12 girls and ten boys, their mean age was 28 months ( 8 to 60$)$. In 11 of these patients the DDH had been neglected, four had been treated with a Pavlik harness and seven with a hip spica. None had undergone prior hip surgery.

The specimens from the club foot and the control hips were immediately fixed in Zamboni's solution consisting of $4 \%$ paraformaldehyde in $0.2 \mathrm{~mol} / \mathrm{l}$ and Sorensen phosphate buffer, $\mathrm{pH} 7.3$ containing $0.2 \%$ acid, for 24 hours at $4^{\circ} \mathrm{C} .{ }^{19}$ After rinsing in $0.01 \mathrm{M}$ phosphate buffered saline (PBS) the specimens were soaked in $20 \%$ sucrose solution for 48 hours. Tissue blocks were prepared in a Tissue Tek O.C.T compound (Sakura Finetek, Tokyo, Japan) to cover the specimen and frozen at $-20^{\circ} \mathrm{C}$ to be used later for immunohistochemical and haematoxylin-eosin analysis.

Animal experiment. In order to compare the density of the nerve fibres in the synovia of the hip and ankle joint, five two-week-old female Sprague-Dawley rats (body-weight 40 to $50 \mathrm{~g}$ ) were used. They were anaesthetised with an intraperitoneal injection of Ketamine $(0.3 \mathrm{mg} / \mathrm{kg})$ and perfused through the ascending aorta with PBS followed by Zamboni's fixative. ${ }^{19}$ The right hip and ankle joints were dissected out and immersed in the above fixative for 24 hours at $4^{\circ} \mathrm{C}$. The joint specimens were subjected to demineralisation in a cacodylate buffered $4 \%$ ethylenediaminetetra-acetic acid solution at $\mathrm{pH} 7.3$ for approximately two weeks as described previously. ${ }^{20}$ After rinsing in PBS the specimens were soaked in $20 \%$ sucrose solution for 48 hours and later tissue blocks were prepared for immunohistochemical analysis and staining with haematoxylin and eosin.

Immunohistochemistry. The specimens were cut on a Leitz cryostat into sections $14 \mu \mathrm{m}$ thick. The frozen sections were mounted directly on super frost chrome alum-gelatin coated glass slides and immunostained according to the avidin-biotin system. The sections were rinsed twice for five minutes in PBS and incubated with 10\% normal goat/horse serum in PBS for 40 minutes to block the non-specific binding. Subsequently, sections were incubated overnight at $4^{\circ} \mathrm{C}$ in a humid chamber with primary antibodies against SP (1:10 000) CGRP (1:10 000), (Peninsula Laboratories; Europe Ltd, St. Helens, UK), PGP 9.5 (1:10 000), (Ultraclone Cambridge Ltd, Cambridge, UK) and GAP 43 (1:2000) (Chemicon International Inc Temecula, California). After the incubation with primary antisera, the sections were rinsed twice in PBS for five minutes and then incubated for 40 minutes at room temperature with biotinylated polyclonal goat anti-rabbit antibodies or monoclonal horse anti-mouse antibodies both 1:250 (Vector Laboratories, Burlingame, California). The monoclonal antibodies were exclusively used to detect GAP 43. Finally, the sections were incubated for 40 minutes with streptavidin-labelled fluorochrome (Cy3 1:5000, Amersham Pharmacia Biotech Ltd., Amersham, UK). Slides were mounted with glycerol-gelatin media. To demonstrate the specificity of the staining, the following controls were included: (a) pre-adsorption of the primary antisera with excess of homologous antigen for 12 hours at room temperature; and (b) omission of either the primary antiserum or the secondary antibody. A Nikon epifluorescence microscope (Eclipse E800, Yokohama, Japan) was used to examine the sections and for photography. T-max black and white and EPL 400 colour films (Kodak, Rochester, New York) were used.

Assessment of immunohistochemical staining. Care was taken to confine examination for the presence of nerve fibres to the superficial and deep layers of synovium of the capsules, avoiding the surrounding loose connective tissue. To confirm the histomorphological features of the capsules, we stained serial sections of each sample with haematoxylin and eosin. We used a scale of + to +++ for the semi-quantitative assessment of nerve fibres identified in each section as described previously: $:^{21}+$, indicates one to four nerve fibres per field as observed with $20 \mathrm{x}$ objective; ++, five to eight fibres; and +++, nine or more fibres. In two sections of each sample the number of nerve fibres positive to each neuropeptide was determined in three fields per section under $20 \mathrm{x}$ magnification and expressed as a mean value. A person (NA) well-versed in immunofluorescence microscopy carried out the semi-quantitative analyses in a double-blind manner. 

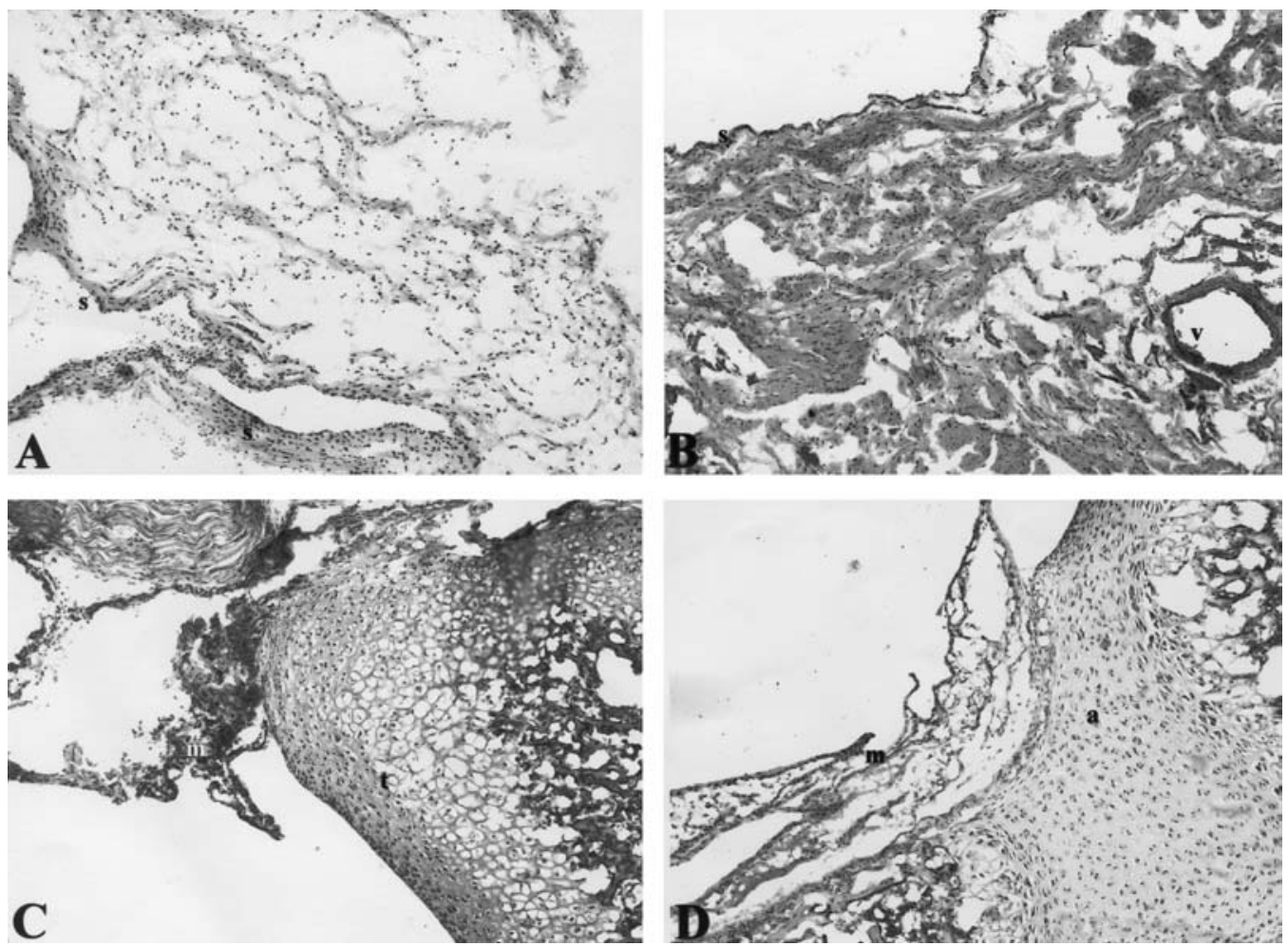

Fig. 1

Photomicrographs of haematoxylin- and eosin-stained sections of A) club foot and B) DDH (control) synovium. The haematoxylin and eosin stained sections of C) the rat hip and D) ankle joints show the synovial membrane. Similar histological features can be seen between A) and B) and between $C$ ) and D). (s, superficial layer of synovium, $v$, blood vessel, m, synovial membrane, $\mathrm{t}$, articular cartilage of distal tibia and a, articular cartilage of acetabulum, x50).

Statistical analysis. The mean and one standard deviation (SD) were used as measures of central tendency and variation, respectively. Data were tested for normality using the Anderson-Darling test. The Wilcoxon-Mann-Whitney signed rank test non-parametric analysis of variance was used to test the differences between the two groups. Values were considered significant at $\mathrm{p}<0.05$.

\section{Results}

Histological examination. The typical morphological features of the synovial membrane were confirmed by haematoxylin and eosin staining in all the human and animal joint capsules (Fig. 1). The similarity between the specimens from club foot and DDH in humans (Figs $1 \mathrm{a}$ and $1 \mathrm{~b}$ ) and those of the hip and ankle joint in the rat (Figs 1c and 1d) were noted. Immunohistochemistry. Nerve fibres immunoreactive to SP, CGRP and PGP 9.5 were seen in the synovial membrane of all the specimens from club feet and DDH. In six samples from club foot and DDH, GAP 43-positive fibres were also identified in the synovium. In addition, CGRP-positive nerve fibres were demonstrated in the synovium of the ankle and hip joints of the rats. In general, the number of nerve fibres immunoreactive to SP, CGRP and PGP 9.5 was significantly less in the synovia in club foot than in $\mathrm{DDH}$ and this was most marked in the values of PGP 9.5, the neuronal marker for mature nerve fibres.

CGRP. These were identified both in the superficial and deep layers of the synovial membrane of the club feet and the control (DDH). They were mainly present as thin, varicose nerve terminals in the synovium (Figs $2 \mathrm{a}$ and $2 \mathrm{~b}$ ). In the deeper layer of the synovium, abundant CGRP-positive nerve terminals were present around the blood vessels especially in the control samples.

$S P$. The occurrence of SP-positive nerve fibres was almost identical to that of CGRP in the synovial membrane of the club-feet and of the controls (DDH). SP-positive fibres, however, occurred predominantly as thin, varicose, nonvascular nerve terminals in the synovium (Figs $2 \mathrm{c}$ and $2 \mathrm{~d}$ ). A species difference was observed in the innervation pattern between the human and the rat with regard to the SP- and CGRP-positive fibres in the synovial membrane. Previous studies from our laboratory have demonstrated a predominance of CGRP-positive fibres compared with SP-positive fibres in the synovium of the rat. ${ }^{22}$ In the human study, SPpositive fibres were more abundant than the CGRP-positive in the synovial membrane.

PGP 9.5. These were the most abundant both in club foot and control synovia. They were seen in nerve bundles as 

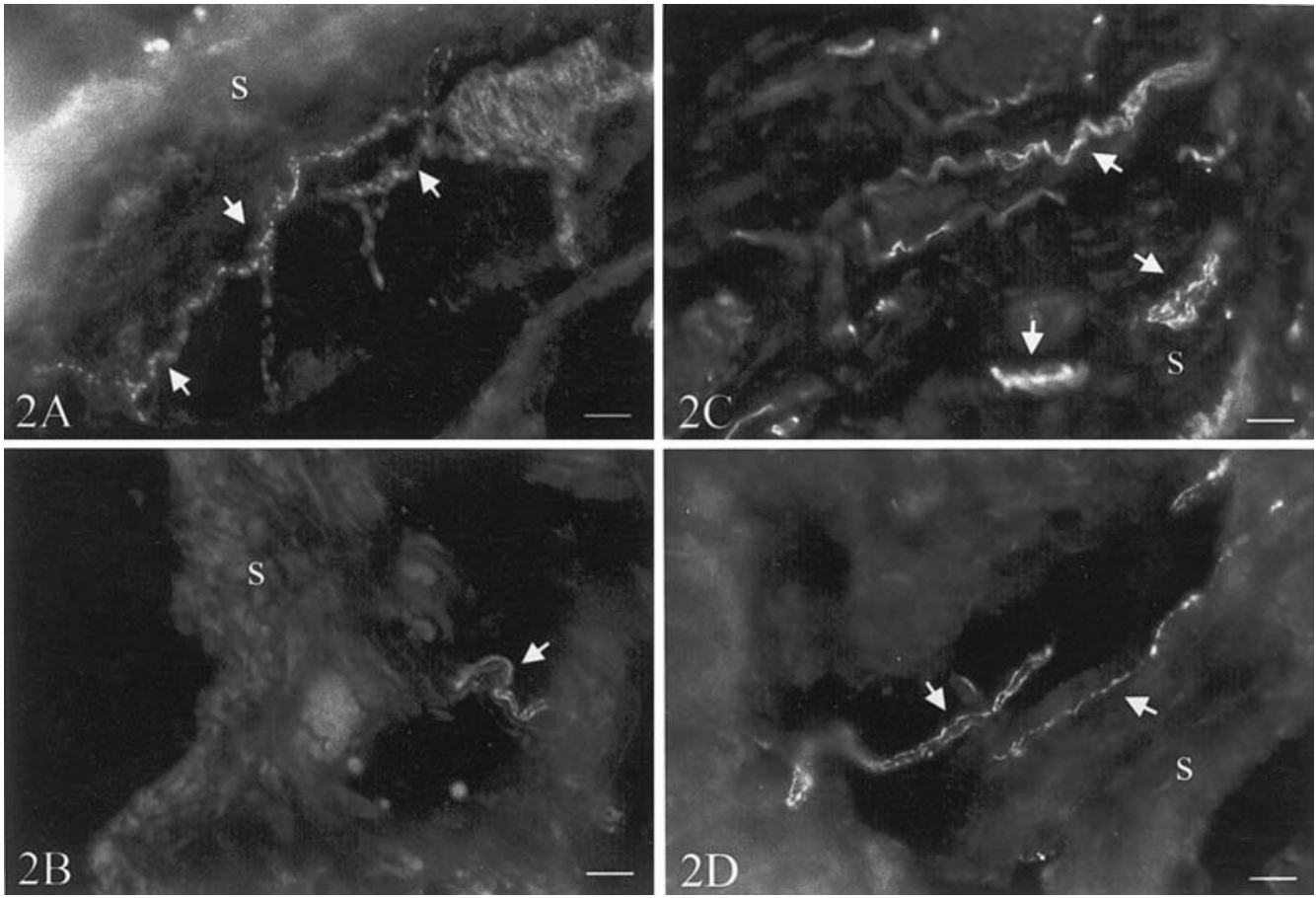

Fig. 2

Immunofluorescence micrographs showing sections of A) and C) DDH (control) and B) and D) of club foot synovium after incubation with antiserum to $\operatorname{CGRP}(A, B)$ and SP (C, D). The density of nerve fibres (arrows) positive to CGRP and SP was more in the control (A, C) compared with club foot synovium (B, D). (s, synovial membrane; bar, $50 \mu \mathrm{m}$ ).
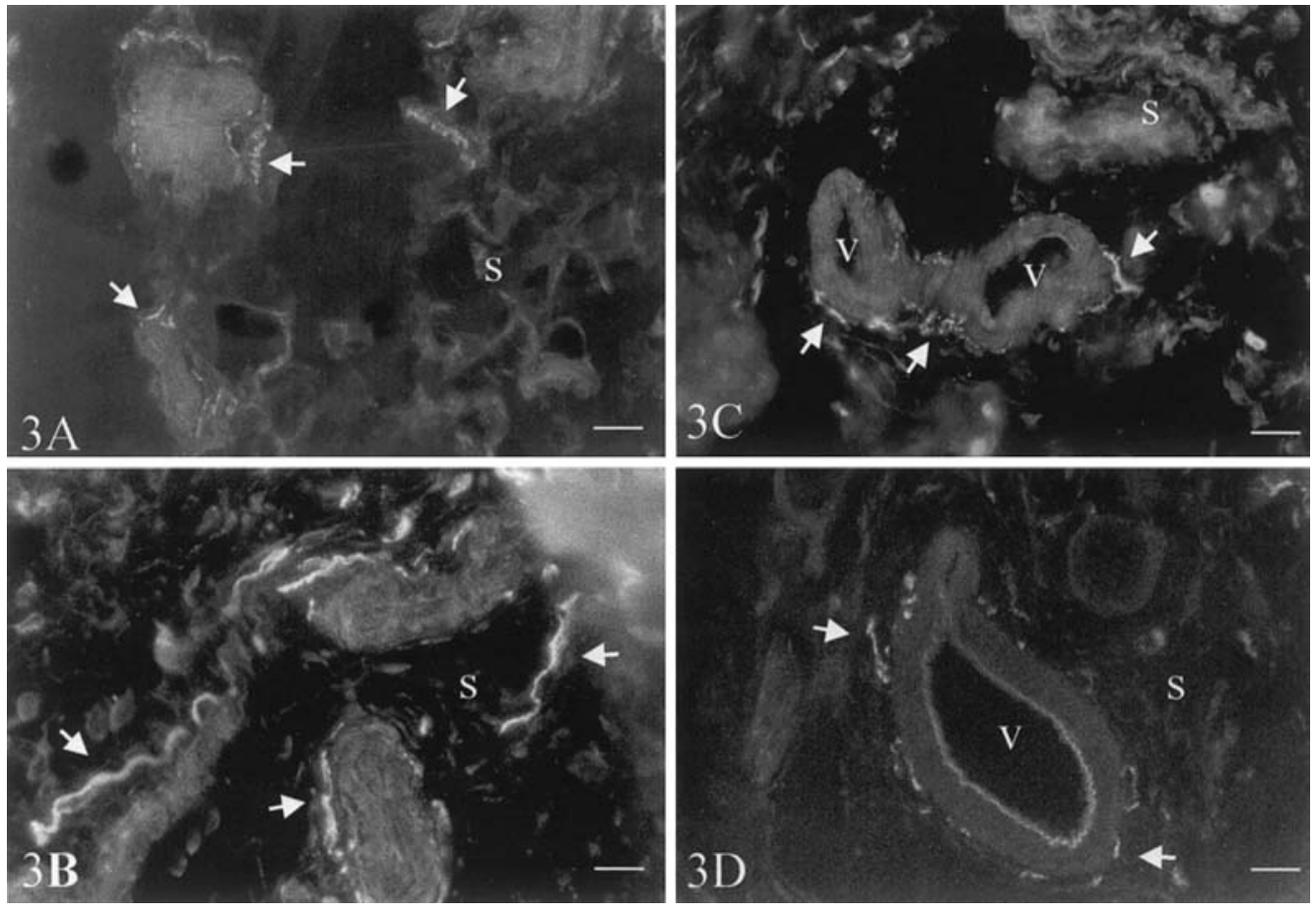

Fig. 3

Immunofluorescence micrographs of sections of A) and C) DDH (control) and B) and D) club foot synovium after incubation with antiserum to PGP 9.5. The density of nerve fibres (arrows) positive to PGP 9.5 was more in control (A, C) compared with club foot synovium (B, D). PGP 9.5-positive nerve fibres (arrows) are seen in the walls of synovial blood vessels in control (C) and club foot (D) capsules. (s, synovial membrane; v, blood vessel; bars, $50 \mu \mathrm{m}$ in A, C, D and $100 \mu \mathrm{m}$ in B). 

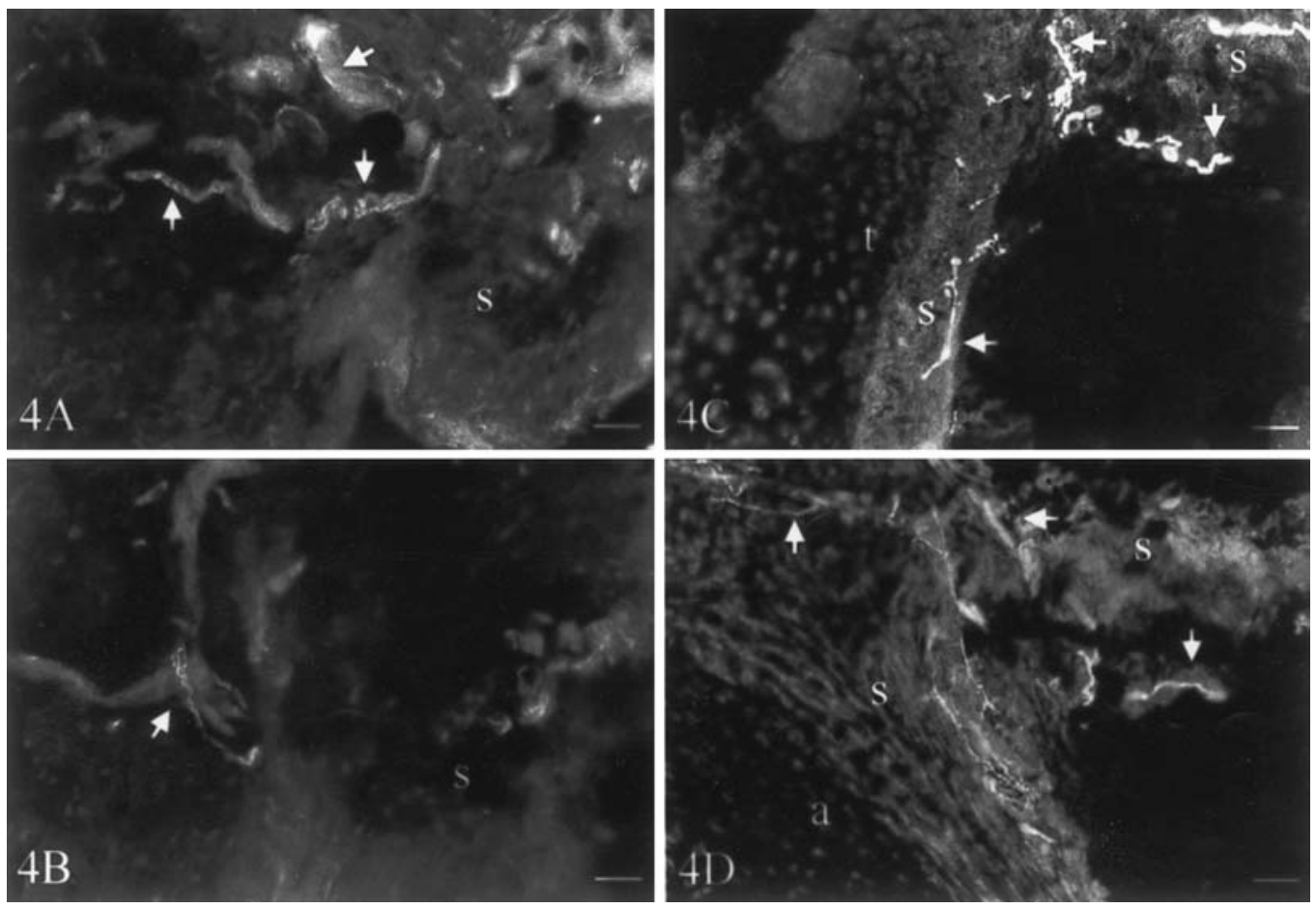

Fig. 4

Immunofluorescence micrographs of sections of A) DDH (control) and B) club foot synovium after incubation with antiserum to GAP 43. More GAP 43-positive nerve fibres (arrows) were seen in control (A) compared with club foot (B) synovium. Immunofluorescence micrographs of sections of C) rat hip and D) ankle joints after incubation with antiserum to CGRP. The density of CGRP-positive nerve fibres (arrows) in the synovial membrane of the rat hip and ankle joint was similar. (s, synovial membrane; t, articular cartilage of distal tibia; a, articular cartilage of acetabulum; bar, $50 \mu \mathrm{m}$ ).

well as in free nerve endings (Figs $3 \mathrm{a}$ and $3 \mathrm{~b}$ ). Abundant nerve fibres, immunoreactive to PGP 9.5, were observed as networks in the walls of blood vessels (Figs $3 \mathrm{c}$ and $3 \mathrm{~d}$ ), but there were more vascular nerve fibres in control specimens (Fig. 3c) compared with those from the club feet (Fig. 3d). GAP 43. These were seen in the synovia of both the club feet and the controls. The fibres were present predominantly as thin, varicose nerve terminals (Figs $4 a$ and $4 b$ ). Many GAP 43-positive fibres were also identified as nerve terminals in the walls of blood vessels. Although no quantitative analysis was undertaken, there seemed to be less GAP-positive fibres in the club feet compared with the controls.

Rat joint capsules. In the capsules of the hip and ankle joints of the rats, abundant CGRP-positive fibres were observed in the synovium (Figs. $4 \mathrm{c}$ and $4 \mathrm{~d}$ ). The occurrence and distribution of CGRP-positive nerve fibres was similar in the synovial membrane of the hip and ankle joints in the rats.

Analysis of the density of the nerve fibres. Semi-quantitative analysis showed that, compared with the controls, the number of positive nerve fibres was $28 \%$ less for CGRP ( $p$ $<0.01), 36 \%$ less for SP $(\mathrm{p}<0.001)$ and $52 \%$ less for PGP 9.5 ( $\mathrm{p}<0.0001)$ in the club feet synovia (Fig. 5). No difference in the density of CGRP-positive nerve fibres was observed between the synovia of the hip and ankle joints in the rat (Fig. 6).

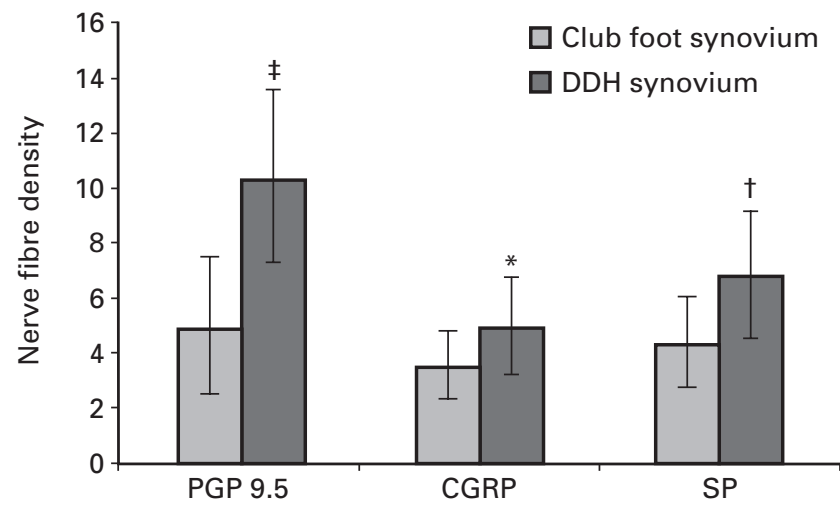

Fig. 5

Histogram illustrating mean density of nerve fibres (number of fibres per high-power field) immunoreactive to PGP 9.5, CGRP and SP in club foot $(\mathrm{n}=24)$ and $\mathrm{DDH}(\mathrm{n}=22)$ synovia. Error bars, $1 \mathrm{SD}$. Significant difference between club foot and DDH is: ${ }^{*} p<0.01 ; \uparrow p<0.001 ; \neq p<0.0001$.

\section{Discussion}

Our study shows that the number of sensory (SP, CGRP) and mature (PGP 9.5) nerve fibres was significantly less in the synovium of the subtalar joint in club foot compared with the hip joints in children with DDH and fewer new or regenerating nerve fibres (GAP 43) were seen. 


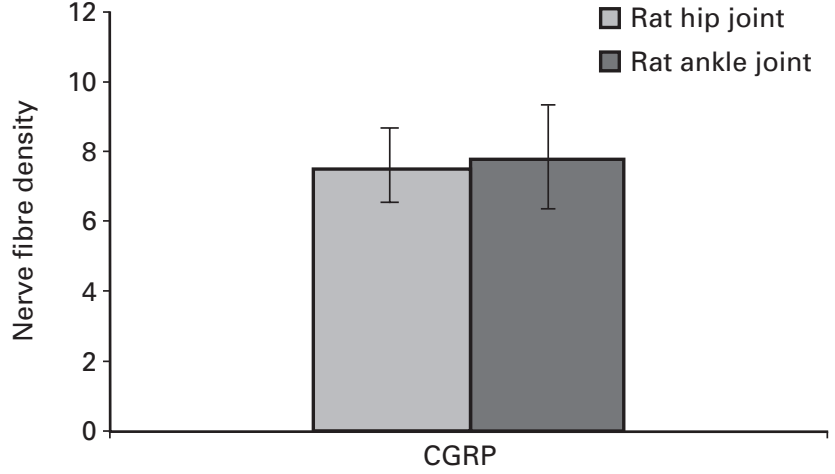

Fig. 6

Histogram illustrating mean density of nerve fibres (number of fibres per high-power field) immunoreactive to CGRP in the synovia of rat hip ( $\mathrm{n}=$ $5)$ and ankle $(n=5)$ joints. Error bars, 1 SD. No difference in nerve fibre density was observed between hip and ankle joints.

Due to ethical reasons, it was not possible to use identical joint capsules from normal individuals. In most previous comparative studies control samples were obtained from cadavers or aborted fetuses in order to examine the histomorphometric and immunohistochemical characteristics of club-foot. ${ }^{12,23-27}$ In our study, the density of nerve fibres in the synovium of the subtalar joint in patients with idiopathic club foot was compared with that from the hip joint in patients undergoing surgery for idiopathic developmental dysplasia. These latter children were used as controls. Histological analysis showed that the morphological features of the synovium from the two sites were very similar. In a separate animal study, we investigated the difference in density of the nerve fibres in the synovium of the hip and ankle joints in two-week-old rats. No difference in the density of CGRP-positive nerve fibres was seen. This suggests that our results using specimens from dysplastic hips as controls are valid.

Various congenital and acquired neurogenic disorders may result in a club-foot deformity. Congenital spinal defects such as myelomeningocele, spinal bifida, and diastematomyelia, and acquired neuronal diseases, including poliomyelitis and cerebral palsy, create a paralytic musculoskeletal deformity, which resembles club foot. ${ }^{1}$ In these conditions muscle imbalance secondary to the neurogenic deficit causes contracture, subluxation, possible dislocation and gross deformity. In the majority of children with idiopathic club foot a definite neurological deficit is hard to demonstrate, although atrophy of calf muscles is seen clinically. Abnormal muscle development or a disproportion of type- 1 muscle fibres has also been implicated, but it is uncertain whether this is the result of atrophy secondary to skeletal deformity or a primary hypoplasia. ${ }^{2,3,28}$ It is also not clear whether the neurological deficit, if any, is central or peripheral.

Histological studies of the lower lumbar spinal cord of the human fetus with unilateral club-foot deformity have shown that the neural canal at 24 weeks gestation was still not closed on the dorsal aspect at and distal to the L5 level. ${ }^{24}$ The same author in another study of the human fetus demonstrated a $40 \%$ reduction of anterior motor neurones on the club foot side of the cord. ${ }^{27}$ This study also demonstrated a reduction in the number and size of the nerve bundles lying adjacent to the spinal cord. ${ }^{27}$ It was concluded that the central and peripheral neurogenic deficit would correlate with the clinical picture of different types of club foot deformity and permanent wasting of the calf muscles, respectively. Our study demonstrates a peripheral neurological deficit by showing a significant reduction in the number of sensory and mature nerve fibres in the synovium in club foot. A number of experimental studies have demonstrated that in denervated muscles, sensory reinnervation significantly retarded muscle atrophy highlighting the role of sensory nerves in preserving muscle mass. ${ }^{29,30} \mathrm{In}$ club foot, atrophy and shortening of the calf and posteromedial muscles may be due to fibrosis secondary to abnormal innervation. ${ }^{2,28}$

There are a number of electrophysiological studies on the muscles of the leg and foot in idiopathic club foot. The results varied from normal ${ }^{31}$ to those showing neurogenic and myopathic alteration. ${ }^{32,33}$ Feldbrin et $\mathrm{al}^{32}$ demonstrated pathological electrophysiological findings in $66 \%$ of conservatively treated patients, whereas in 43 patients treated surgically, all those with fair and poor results had pathological electrophysiological findings and 12 required further operations. These results were substantiated by another study where somatosensory evoked potentials (SSEPs) and motor electrophysiological tests were carried out in children with surgically-corrected club feet. ${ }^{33}$ The study showed abnormal SSEPs or motor electrophysiological tests in $46 \%$ of club feet. Furthermore, the study disclosed an association between neurological abnormality and the severity of deformity in club foot and its response to surgical treatment. Only a fair surgical outcome was observed in grade-3 club-foot deformity with neurological abnormality. ${ }^{33}$ Our results showing significant sensory hypoinnervation in the synovium in club foot may explain the abnormal SSEP shown in the above study.

There is accumulating evidence that the nervous system participates in musculoskeletal development and fracture healing. ${ }^{5,7,8,11}$ Previously, in ontogenic studies of the hindlimb of the rat, we have shown that the expression of the sensory and autonomic neuropeptides appeared to coincide with the process of mineralisation. ${ }^{34,35}$ In human and animal studies, peripheral denervation of the hind-limb significantly reduces the size of the tibia, the gastrocnemius muscle and the foot showing a trophic effect of peripheral nerves on the development of bone and joint tissues. . $^{4,5,36-38}$ It seems that neuronal homeostasis in conjunction with growth factors is required for the physiological growth of target organs. It is possible that in patients with idiopathic club foot, deficiency of sensory neuropeptides may lead to fibrosis and soft-tissue contractures. Recurrence after surgi- 
cal correction of the deformity may be due to the inherent pattern of hypoinnervation seen in the synovium and probably other surrounding soft tissues.

Another factor leading to soft-tissue contraction may be abnormality of local angiogenesis and the blood supply. There is a wide variety of neuronal efferent actions on cell proliferation, cytokine expression, immune response, and inflammation. ${ }^{17,18,39,40}$ Both the sensory neuropeptides, SP and CGRP, participate in the regulation of fibroblasts and synoviocyte proliferation and angiogenesis. ${ }^{16,18,41,42}$ The present study showed an overall, as well as localised, reduction of sensory (SP, CGRP) and mature (PGP 9.5) nerve fibres around the walls of blood vessels in the synovium in club foot. Although no studies of regenerating nerve fibres were made, GAP 43-positive fibres were less in the synovium indicating scarce delivery of neuropeptides in the target organ. The study demonstrated not only a reduction in the density of sensory nerve fibres but also the deficient delivery of neuroactive substances. The potent vasodilatory effects of SP and CGRP are well known and reduced innervation of blood vessels containing sensory neuropeptides may be responsible for poor blood supply to the joint capsule in club foot. ${ }^{14,16}$ Recent studies have demonstrated the cytocontractile proteins desmin, vimentin and myofibroblasts in club foot specimens in the fetus as well as in grown children. ${ }^{26} \mathrm{It}$ was suggested that recurrences after soft-tissue release could be attributed to the continued presence of cytocontractile elements. It is known that during cell formation there is a gradation of cells from fibroblasts to myofibroblasts. It is tempting to suggest that the lack of a normal sensory input to the fibroblasts may lead to an early and increased number of myofibroblasts causing soft tissue contraction.

Our study showed significant reduction of sensory and mature nerve fibres in the synovium of the subtalar joint in club-foot which supports a neuronal origin as a cause of the deformity. A local imbalance of neutrophic factors may contribute to the soft-tissue contracture leading to a clubfoot deformity.

No benefits in any form have been received or will be received from any commercial party related directly or indirectly to the subject of this article.

\section{References}

1. Peretti G, Surace A. Club foot, classification, etiology and pathogenesis. Ital J Orthop Traumatol Supp/ 1976;2:11-37.

2. Isaacs H, Handelsman JE, Badenhorst M, Pickering A. The muscles in club foot a histological histochemical and electron microscopic study. J Bone Joint Surg [Br] 1977:59-B:465-72

3. Gray DH, Katz JM. A histochemical study of muscle in club foot. J Bone Joint Surg [Br] 1981;63-B:417-23.

4. Curtiss PH, Tucker HJ. Sciatic palsy in premature infants: a report and follow-up study of ten cases. JAMA 1960;174:1586-8.

5. Combes MA, Clark WK, Gregory CF, James JA. Sciatic nerve injury in infants: recognition and prevention of impairment resulting from intragluteal injections. J Am Med Assoc 1960;173:1336-9.

6. McCredie J. Embryonic neuropathy: a hypothesis of neural crest injury as the pathogenesis of congenital malformations. Med J Aust 1974;1:159-63.

7. McCredie J, North K, de Longh R. Thalidomide deformities and their nerve supply. J Anat 1984;139:397-10.

8. Hardy SG, Dickson JW. Pathological ossification in traumatic paraplegia. J Bone Joint Surg [Br] 1963;45-B:76-87
9. Drennan JC, Freehafter AA. Fractures of the lower extremities in paraplegic children. Clin Orthop 1971;77:211-17.

10. Nottage WM. A review of long bone fractures in patients with spinal cord injuries. Clin Orthop 1981;155:65-70.

11. Freehafer AA. Limb fractures in patients with spinal cord injury. Arch Phys Med Rehabil 1995;76:823-7.

12. Ippolito E, Ponseti IV. Congenital club foot in the human fetus: a histological study. $J$ Bone Joint Surg [Am] 1980;62-A:8-22.

13. Strand FL, Rose KJ, Zuccarelli LA, et al. Neuropeptide hormones as neutrophic factors. Physiol Rev 1991;71:1017-46.

14. Hokfelt T, Broberger C, Xu ZZ, et al. Neuropeptides - an overview. Neuropharmacology 2000;39:1337-56.

15. Oku R, Satoh M, Fuji N, et al. Calcitonin gene-related peptide promotes mechanical nocieption by potentiating release of substance $\mathrm{P}$ from the spinal dorsal horn in rat. Brain Res 1987; 403:350-4.

16. Brain SD, Williams TJ, Tippins JR, Morris HR, Maclntyre I. Calcitonin generelated peptide is a potenti vasodilator. Nature 1985;313:54-6.

17. Brain SD, Williams TJ. Interactions between the tachykinins and calcitonin generelated peptide lead to the modulation of oedema formation and blood flow in rat skin. Br J Pharmacol 1989;97:77-82.

18. Haegerstrand A, Dalsgaard CJ, Jonzon B, Larsson 0, Nilsson J. Calcitonin gene-related peptide stimulates proliferation of human endothelial cells. Proc Nat Acad Sci USA 1990;87:3299-303.

19. Zamboni L, De Martino C. Buffered picric acid-formaldehyde: a new, rapid fixative for electron microscopy. J Cell Biol 1967;35:148.

20. Bjurholm A, Kreicbergs A, Schultzberg M. Fixation and demineralization of bone tissue for immunohistochemical staining of neuropeptides. Calcif Tissue Int 1989;45. 227-31.

21. Ahmed M, Bergstrom J, Gillespie WJ. Autonomic neuropeptides in the interface membrane of aseptic loose hip prostheses. J Arthroplasty 1999;14:594-602.

22. Bjurholm A, Kreicbergs A, Brodin E, Schultzberg M. Substance P- and CGRPimmunoreactive nerves in bone. Peptides 1988;9:165-71.

23. Irani RN, Sherman MS. The pathological anatomy of idiopathic clubfoot. Clin Orthop 1972;84:14-20

24. Swart JJ. Club foot: a histological study. SA Bone Joint Surg 1993:3:17-23.

25. Fukuhara K, Schollmeier G, Uhthoff HK. The pathogenesis of club foot: a histomorphometric and immunohistochemical study of fetuses. J Bone Joint Surg [Br] 1994;76-B:450-7.

26. Sano H, Uhthoff HK, Jarvis JG, Mansingh A, Wenckebach GF. Pathogenesis of soft-tissue contracture in club foot. J Bone Joint Surg [Br] 1998;80-B:641-4.

27. Swart JJ. Congenital talipes equinovarus: an intrauterine paralysis. J Bone Joint Surg [Br] 2000;82-B(Suppl II):183-4.

28. Handelsman JE, Badalamente MA. Neuromuscular studies in clubfoot. J Pediat Orthop 1981:1:23-32.

29. Dautel G, Lineaweaver WC, Campagne-Pinto D, Buncke HJ. Preservation of transplanted muscle mass by motor and sensory reinnervation. In: Freilinger $G$ Deutinger $\mathrm{M}$, eds. Transection of the third Vienna muscle symposium. Vienna: Blackwell-MZA 1992:96.

30. Zhang E, Lineaweaver WC, Ustuner T, et al. Comparison of muscle mass preservation in denervated mucle and transplanted muscle flaps after motor and sensory reinnervation and neurotization. Plast Reconstr Surg 1997;99:803-14

31. Bill PL, Versfeld GA. Congenital clubfoot: an electromyographic study. J Pediat Orthop 1982:2:139-42.

32. Feldbrin Z, Gilai AN, Ezra E, et al. Muscle imbalance in the aetiology of idiopathic club foot: an electromyographic study. J Bone Joint Surg [Br] 1995;77-B:596-601.

33. Macnicol MF, Nadeem RD. Evaluation of the deformity in club foot by somatosensory evoked potentials. J Bone Joint Surg [Br]2000;82-B:731-5.

34. Sisask G, Bjurholm A, Ahmed M, Kreicbergs A. Ontogeny of sensory nerves in the developing skeleton. Anat Rec 1995:243:234-40.

35. Sisask G, Bjurholm A, Ahmed M, Kreicbergs A. The development of autonomic innervation in bone and joints of the rat. J Auton Nerv Syst 1996;59:27-33.

36. Dietz FR. Effect of peripheral nerve on limb development. J Orthop Res 1987:5:576-85

37. Dietz FR. Effect of denervation on limb growth. J Orthop Res 1989;7:292-303

38. Edoff K, Hellman J, Persliden J, Hilderbrand C. The developmental skeletal growth in the rat foot is reduced after denervation. Anat Embryol 1997;195:531-8.

39. Lotz M, Vaughan JH, Carson DA. Effects of neuropeptides on the production of inflammatory cytokines by human monocytes. Science 1988;241:1218-21.

40. Berczi I, Chalmers IM, Nagy E, Warrington RJ. The immune effects of neuropeptides: Baillieres Clin Rheumatol 1996;10:227-57.

41. Nilsson J, von Euler AM, Dalsgaard CJ. Stimulation of connective tissue cell growth by substance P and substance K. Nature 1985;315:61-3.

42. Yule KA, White SR. Migration of $3 Т 3$ and lung fibroblasts in response to calcitonin gene-related peptide and bombesin. Exp Lung Res 1999;25:261-73. 